\title{
The Effect of Critical Thinking Techniques for improving EFL Reading Skills
}

\section{Mohammed Ahmed Hammed Okasha}

English Language Institute, Jazan University, Jazan, Saudi Arabia

\section{Abstract}

7 he present study aimed at investigating the effectiveness of critical thinking techniques for improving EFL reading skills. The design of this study is a pre-post, experimental-control group. The experimental group students were taught using critical thinking techniques, while the control group did not receive any training except the regular method. The main question raised in this study was what is the effect of critical thinking techniques in improving EFL reading skills? To this end, the researcher collected data through a reading test and a rubric for correcting it, prepared by the researcher, and judged by the jury members. The reading test was applied to the study sample before and after the implementation. The results of the study revealed that EFL reading selected skills "inference, evaluation, and recognizing vocab." improved among experimental group students because of using critical thinking techniques "debate, problem-solving, self, and pair assessment". This reveals the effectiveness of critical thinking techniques in developing EFL reading skills among Jazan University students. The researcher recommends using new techniques to develop EFL reading skills.

Keywords: Critical thinking, EFL reading skills

\section{Introduction}

In this fast-paced and ever-changing world we live in, reading skill is not a mere luxury; it has been considered by many scholars a basic survival skill. According to Okasha,(2020) reading is an essential skill for success in real life, and it is a a process of thinking, evaluating, judging, imagining, reasoning, and problem-solving. In the 21 st century, the concern is how to let learners create information, share it and most importantly to perform a 
critical assessment of any content (Gretter \& Yadav, 2016). Consequently, there is a close relation between reading as an important learnt skill and the critical thinking as a techenique to control and mange it. Petrucco \& Ferranti (2017) highlighted the importance of critical thinking as one of the required competencies to be learned and developed by students to master reading skills.

Yurika (2008) states that helping students learn to use their reading skills needs continuous reading practice to help them become independent in their learning. She states that when good readers decide about the text, they may set their purpose for reading, engage in a dialogue with the author, and thus become active readers. Reading is a problem-solving situation and this is one of the main features of crtical thinking that involves taking all the text cues and information from prior knowledge into account. As a pedagogically fact, learners need to become active readers by solving problems if they are truly to understand texts.

Fok (2002) points out there is no apparent reason for learners to think critically when others do all the thinking for them. Having other people make decisions relieve students of responsibility. The leaners' centerd approach in reading gives readers a big space to express their thoughts freely and without any kind of reluctance as some students may think that their judgment is inferior to that of an authoritative figure. Consequently, the teacher's main role is to encourage and support students to think while reading. Many students come from backgrounds in which they are instructed to obey authority, which implies that they are not ready to make decisions on their own. They need to look to older, wiser, and more informed people to tell them what to 
do. Some students are accustomed to learning information by heart rather than thinking about it. According to Basri et al (2019) readers can use critical thinking skills to understand, interpret, and assess what they hear or read in order to formulate appropriate reactions or responses. Out of the field of teaching, it has mainly observed that teachers are teaching students what to think rather than how to think effectively about the subject matters. This technique blocks the students' thinking seriously, about what they learn. Consequently, the researcher proposed this study to focus on critical thinking techniques for improving EFL reading comprehension skills to give students room to discuss, express their opinions, and evaluate what they are doing.

Reading is an interactive process between the text and the reader. A reader corrects and refines concepts through each new reading experience. Part of a reader's reaction involves making judgments about the worthiness of what is read. Some responses are emotional, while others may be intellectual assessing the truth of what is read. Recent research on reading comprehension indicates that reading is an interactive process between the text and the reader and that comprehension occurs when the reader successfully connects what is presented in the text with what s/he already knows or wants to know. Dorn and Soffos (2005) believe that comprehension is a constructive process, personalized by the ideas and thoughts of the individual readers.

\section{Critical Thinking}

According to Astleitner (2007), critical thinking is a higher-order thinking skill which includes evaluating 
arguments, and is a purposeful, self-regulatory judgment which ends in interpretation,analysis and evaluation. Teachers should model and practice critical thinking and critical attitudes in authentic situations. Students should learn to think critically when they have the opportunities and reason to think in critical ways. Some educators have pronounced the need for students to actively participate in the critical thinking process and be aware of what they are learning and why they are learning critical thinking.

Birjandi \& Bagherkazemi (2010) highlighted that critical thinkers are those who:

- Identify problems and focus on relevant topics and issues.

- Distinguish between valid and invalid inferences.

- Suspend judgments and decisions in the absence of sufficient evidence.

- Accurately explain their decisions.

- Curb their emotional reactions to others' arguments.

- Determine the truth or falsity of assumptions.

- Distinguish between primary and secondary sources of information.

- Distinguish opinions from facts.

- Draw inferences.

- Formulate and ask appropriate questions.

- Gather data from multiple sources relevant to a problem to be solved or a decision to be made.

- Listen attentively to others and provide them with appropriate feedback.

- Assess and evaluate statements.

- Have a keen sense of curiosity.

- Open to criticisms. 
- Able to assess themselves.

\section{Critical thinking and reading comprehension}

Richard \& Linda (2016) stressed that there is a close connection between critical thinking and reading comprehension as the reflective mind improves its thinking by reflectively thinking about it. Likewise, the reflective mind improves its reading by reflectively thinking about how it is read. Elder and Paul (2004) considered critical thinking as the art of close reading. They emphasized the importance of engaging oneself in constant questioning while reading. Paul (2005) demonstrated that learners could improve reading by reflectively thinking about what and how they read. He said learners should be engaged actively in different critical thinking processes, such as analysis of ideas, discussion, and reflection through writing. Yuretich (2004) asserted that students should ponder a question, discuss it in groups, or explain their answers to others by doing so; they are more likely to use skills at the more advanced levels of Bloom's Taxonomy.

Paul (2005) pointed out that turning students into active questioners is a significant part of critical thinking education. Learners need to keep asking questions in the learning process to learn properly. They stated that deep questions drive thought beneath the surface of things, forcing students to deal with complexities.

\section{Reading Comprehension Skills}

Rasinski (2000) proposed five levels of comprehension skills:

\section{Literal:}

Literal comprehension focuses on information, which is explicitly stated in the text. There is a danger that this need 
does not involve true understanding at all: it cannot be any more than a demand for the mechanical repetition of what is plainly stated in the text.

\section{Reorganization:}

At this level, the student has to organize for himself/ herself some of the information explicitly expressed. S/He may have to summarize information or handle it in a different sequence. For instance, if s/he has been told that (B) happened after (A), s/he may be asked what happened first

\section{Inferential:}

Here, the student is required to go beyond the immediate text. S/He has to make use of his/her use of experience and intuition, and possibly predict outcomes. A question set at this level might begin with something like this: 'From what you have read do you think that Mr. Smith really wants to sell the house, or possibly being forced into it?

\section{Evaluative}

This level of response requires the student to make judgments. This may require him/her to make use of his/ her knowledge of a particular subject. An appropriate question might be "To what extent do you think the writer has provided adequate support for his/her conclusion that...?'

\section{Appreciative}

In this advanced level of response to a text, the student has to be emotionally and aesthetically sensitive to what s/he is reading. It requires some appreciation of literary techniques. 
The researcher chose inferential, evaluative, and recognizing vocab comprehension skills to be taught in this study and to see the effect of the critical thinking techniques on these skills.

\section{Experimental Design}

\section{Study Design}

The present study utilized the quasi-experimental research design, and a pre-post reading test for evaluating students' critical thinking practice in a reading task. The experimental group and the control group had a pre and post-test. The experimental group received training via using critical-thinking techniques while the control group did not receive such training.

\section{Study Sample Participants}

The sample Participants of the present study consisted of 70 students from Jazan University. They were chosen from the second level in English section enrolled in English Language Institute at Jazn University, Kingdom of Saudi Arabia. They were divided into two groups; an experimental group $(\mathrm{N}=35)$ and a control group $(\mathrm{N}=35)$. The experimental group was taught reading skills through using critical thinking techniques, while the control group was taught by the regular method.

\section{Variables of the Study}

\section{The independent variable}

The use of critical reading techniques included (debate, problem-solving, self, and pair assessment).

\section{The dependent variable}

EFL reading skills that included (inference, evaluation, and recognizing vocab. skills). 


\section{Study Purpose}

The study aimed at improving students' EFL reading comprehension skills via using critical thinking techniques.

\section{Study questions}

The present study was an attempt to answer the following main question:To what extent are the critical thinking techniques effective in improving reading Skills for Jazan University students?

From this question, the following sub-questions emerge:

- To what extent are the critical thinking techniques effective in improving reading inference?

- To what extent are the critical thinking techniques effective in improving reading evaluation?

- To what extent are the critical thinking techniques effective in improving reading recognition vocab.

\section{Study Hypotheses}

The present study attempted to test the following hypotheses:

1. There would be a statistically significant difference between mean values obtained by the students of the experimental and the control groups on the postperformance test of the reading skill (inference) in favor of the experimental group.

2. There would be a statistically significant difference between mean values obtained by the students of the experimental and the control groups on the postperformance test of the reading skill (evaluation) in favor of the experimental group. 
3. There would be a statistically significant difference between mean values obtained by the students of the experimental and the control groups on the postperformance test of the reading -skill (recognisig vocab.) in favor of the experimental group.

\section{Study Instruments}

The tools of the present study were:

1. Critical thinking techniques (debate, problemsolving, self, and pair assessment).

2. A reading test

3. A rubric for grading the reading test

\section{Training program}

The period of this study lasted for ten sessions in two months. Each session lasted for 45 minutes. The first two sessions were devoted to orientation to let students know how to use critical thinking techniques. The techniques adopted in this study were as follows:

\section{A. Debate}

The debate is considered as a technique of critical thinking and reasoned decision-making. It can be tailored for educational purposes to improve critical thinking. Freeley and Steinberg (2000) defined the debate technique as the process of inquiry and a way of arriving at a reasoned judgment on a topic. The debate technique can inspire learners' enthusiasm to critically contemplate topics from different perspectives. To make learners be fully engaged in the debate-reading lesson, the researcher focused on the following items:

- The topics are mainly controversial. 
- The topics are of relevance to the class and the subject matter.

- The topics are interesting and motivating.

- Students know the discussion topics in advance.

- Students are given enough time to mull over the topic from different angles.

- Students have enough opportunities to express themselves freely and critically.

\section{B. Problem Solving Tasks}

One of the distinguishing features of critical thinkers is to be able to raise questions and find pertinent answers for them based on reliable evidence. To do so successfully, the researcher let the students work in pairs and groups to describe the content of the discussion, to define, personalize and discuss the problem and its alternative solutions, and finally evaluate the whole process.

\section{Self \& peer assessment assignments}

Teachers should not disregard learners' views and opinions or suppress them. They should allow learners to express themselves freely to train them to use their thinking skills. Therefore, one way to alleviate this problem is to engage learners in carefully guided self and peer-assessment. Learners should be given a chance to assess not only themselves but also others to enhance their critical thinking aptitude.

To implement the above-mentioned critical thinking techniques, the researcher made full use of the following instructions:

- Giving detailed information about the critical thinking technique to the students. 
- Modeling the technique in front of students.

- Helping students to follow the model in pair and team-work

- Independent performance, students work alone with limited help from the instructor.

There were reading workshops to carry out the abovementioned instructions. The remaining eight sessions were about the training course and evaluating students' performance. The students of the target group were divided into small groups to share their opinions and think about the potential arguments that might come out of their reading to the chosen comprehension texts. This process taught students how to cooperate to promote critical thinking. The researcher taught the target group how to use the debate, problem-solving, and self and pair assessment techniques. The researcher divided the target group into two sides as affirmative and negative. One of the students first would introduce the topic clearly and define the concepts accurately to remove any misconception about the exact meaning of the words. The debate would take place and the debaters would present their opinions through argumentation. After exchanging opinions, the instructor would follow up the debate with a summary of the students' opinions and views, assessing the strengths and weaknesses, let students express their opinions on which side was more convincing. This part is important because it helped students to understand that the process of thinking and debate can lead to tangible results. Students need to work in pairs and groups to describe, define, personalize, and discuss the content of the problem and its alternative 
solutions to evaluate the whole process. Students were motivated to engage in carefully guided self- and peerassessment. Students were given a chance to assess not only themselves but also their classmates'reading tasks to enhance their critical thinking ability. During the training sessions, the instructor tried to teach the students how to distinguish between facts, judgments or opinions, how to prove their claims based on examples, common sense, statistic, and expert opinions. They learned to start the argument with "I think/believe that, because, and therefore. At the end of the experiment, the reading comprehension test which was used at the pre-test was conducted again for both groups to determine the discrepancies between the two groups, to probe the probable positive effect of critical thinking techniques, and to find out the relationship between critical thinking techniques and EFL reading comprehension Skills.

\section{Determining the Reliability of the reading test}

The reliability of the reading test was measured by using the test-retest method. The reading test was administered to a group of second-level students enrolled in English Language Institute at Jazan University, Kingdom of Saudi Arabia. Then, It was administered to the same group again after two weeks. The Pearson correlation between the two administrations was (0.710) at the 0.01 level. Therefore, the reading test was reliable

\section{The Chosen Skills:}

- Inferential skill

- Evaluative skill 
- Recognizing vocab skill

\section{Content of the study}

The training program provided students with rich inputs to help them master the EFL reading comprehension skills through critical thinking techniques. These inputs were as follows:

- Reading passages, dialogue exchange, and written reports.

- Brainstorming and conducting a brief class lesson on the content of the passages.

- Discussing the main ideas in the passages in a debating situation, individual conferences, and whole-class discussion.

\section{Study Results}

There are significant differences at the 0.05 between the post-test mean scores of the experimental and control groups in comprehension skills (inferential, evaluative and recognizing vocab skills) in favor of the experimental group

To investigate this hypothesis, two t-tests were applied to the mean scores of both the experimental group and the control group in the pre-posttest to find out whether the differences between the two groups were statistically significant. To determine the initial equivalence between the two groups before the commencement of the experiment, a t-test was applied to the mean scores of the two groups in the pre-test, including comprehension; see table 1 . 
Table 1: t-test results of the pre-test for both groups in comprehension skills.

\begin{tabular}{|c|c|c|c|c|c|c|}
\hline Skill & Group & N. & Means & S.D & $\mathbf{t}$ & $\mathbf{P}$ \\
\hline \multirow{2}{*}{$\begin{array}{c}\text { Inferential } \\
\text { skill }\end{array}$} & Exp. & 30 & 12.33 & 4.86 & \multirow{2}{*}{.13} & \multirow{2}{*}{.89} \\
\hline & Con. & 30 & 12.50 & 4.68 & & \\
\hline \multirow{2}{*}{$\begin{array}{c}\text { Evaluative } \\
\text { skill }\end{array}$} & Exp. & 30 & 10.66 & 5.04 & \multirow{2}{*}{.38} & \multirow{2}{*}{.70} \\
\hline & Con. & 30 & 9.50 & 4.99 & & \\
\hline \multirow{2}{*}{$\begin{array}{c}\text { Recognizin } \\
\text { g vocab } \\
\text { skill }\end{array}$} & Exp. & 30 & 7.83 & 3.13 & \multirow[b]{2}{*}{.79} & \multirow[b]{2}{*}{.43} \\
\hline & Con. & 30 & 7.16 & 3.39 & & \\
\hline
\end{tabular}

The t-test of the students' performance in inferential skill revealed that the mean score of the treatment group was 12.33 and that of the non-treatment group was 12.50 and that $(\mathrm{t}=13, \mathrm{P}>0.05)$, which is not statistically significant at 0.5 level of confidence. This indicated their equivalence in inferential skill before the commencement of the treatment. The analysis of data revealed that the experimental group's mean score in evaluative skill was 10.66. The control group was 9.50 and that $\mathrm{t}=.38$, which is not statistically significant at 0.05 level of confidence. The same procedure was followed with the vocab skill, where the analysis of data revealed that the mean of the experimental group scores was 7.83 and that of the control group was 7.16 and that $(\mathrm{t}=.79, \mathrm{P}>0.05)$, which is not significant at 0.5 level of confidence.

Table 2: t-test results of the post-test for both groups in comprehension skills.

\begin{tabular}{|c|c|c|c|c|c|c|}
\hline Skill & Group & N. & Means & S.D & $\mathbf{t}$ & $\mathbf{P}$ \\
\hline \multirow{2}{*}{$\begin{array}{c}\text { Inferential } \\
\text { skill }\end{array}$} & Exp. & 30 & 13.33 & 3.79 & \multirow{2}{*}{3.29} & \multirow{2}{*}{$.02 * x$} \\
\hline & Con. & 30 & 10.66 & 4.86 & & \\
\hline \multirow{2}{*}{$\begin{array}{c}\begin{array}{c}\text { Evaluative } \\
\text { skill }\end{array} \\
\end{array}$} & Exp. & 30 & 13.16 & 4.25 & \multirow{2}{*}{3.27} & \multirow{2}{*}{$.02 * *$} \\
\hline & Con. & 30 & 10.16 & 4.42 & & \\
\hline \multirow{2}{*}{$\begin{array}{c}\text { Recognizi } \\
\text { ng vocab } \\
\text { skill }\end{array}$} & Exp. & 30 & 10.33 & 3.69 & \multirow[b]{2}{*}{3.24} & \multirow[b]{2}{*}{$.02 * *$} \\
\hline & Con. & 30 & 7.16 & 3.86 & & \\
\hline
\end{tabular}

** Significant at the 0.01 level. 
The t-test revealed that the mean score of the treatment group in inferential skills, was 13.33, and that of the nontreatment group 10.66; $\mathrm{t}=3.29$ which is statistically significant at the 0.01 level of confidence. The analysis of the evaluative skill, where students answered questions began with what do you think, believe... are you with or against ....and why? The results revealed that the mean score of the experimental group was 13.16 and that of the control group was 10.16 and the observed value of $t=3.27$, which is statistically significant at the 0.01 level of confidence. This result indicated that the students gained the confidence that helped them to evaluate the content of the reading passages. The analysis of vocab skill where the students were asked to answer questions like what does this word refer to or what does this word mean or which word is close to the underlined word? The results revealed that the mean score of the experimental group was 10.33 and that of the control group was 7.16. The value of $t=3.24$, is significant at the 0.01 level of confidence.

\section{Study Recommendation}

This study provides the experts in the field of language teaching with information about the relationship between critical thinking and learners' performance on reading comprehension texts applying critical thinking techniques, debate, problem-solving, self, and pair assessment. The following recommendations should be taken into consideration:

1. There is a need for developing self-confidence in students' abilities to approach reading passages as per their viewpoints. 
2. Teaching can be made learner-centered, with more emphasis on the learning process.

3. Interaction between the teacher-student and studentstudent creates a co-operative, non-threatening, and fear-free environment.

4. Students should be given the chance to take part in activities that strengthen their enthusiasm for writing in English.

5. Students should be encouraged to use critical thinking techniques while dealing with the reading materials of their daily life.

6. The teacher should deal with his students'feedback on reading tasks positively to foster their meaningful interaction with the reading text.

\section{References}

- Astleitner, H. (2007). Teaching critical thinking online. Journal of Instructional Psychology, 29(2), 53-77.

- Basri, H., Purwanto, As'ari, A. R., \& Sisworo. (2019). Critical Thinking Skills, Critical Reading and Foreign Language Reading Anxiety in Iran Context. International Journal of Instruction,12(3), 219-238. https://doi.org/10.29333/iji.2019. $12414 \mathrm{a}$

- Birjandi, P. \& Bagherkazemi, M. (2010). The relationship between Iranian EFL teachers' critical thinking ability and their professional success. ELT, 3(2), 135-145.

- Dorn, L. J., \& Soffos, C. (2005). Teaching for Deep Comprehension: A reading workshop approach. Portland, Maine, Stenhouse Publishers. Retrieved Sep 14, 2008, from www.stenhouse.com

- Elder, L., \& Paul, R. (2004). Critical thinking and the art of close reading (part IV). Journal of Developmental Education, 28(2): 3637. 
- Fok, S. C. (2002). Teaching critical thinking skills in a Hong Kong secondary school. Asia Pacific Education Review, 3(1), 8391.

- Freeley, A. J., \& Steinberg, D. L. (2000). Argumentation and debate: Critical thinking for reasoned decision-making. (10th Ed.).Stamford: Wadsworth.

- Gretter, S., \& Yadav, A. (2016). Computational thinking and media \& information literacy: An integrated approach to teaching twenty-first century skills. TechTrends, 60(5), 510-516.

- Okasha, M. (2020) Using Strategic Reading Techniques for Improving EFL Reading Skills Arab World English Journal,11 (2),311 -322. DOI: https://dx.doi.org/10.24093/awej/vol11no2.22

- Paul, R. (2005). The state of critical thinking today. New Directions for Community Colleges, 130, 27-38.

- Petrucco, C., \& Ferranti, C. (2017). Developing Critical Thinking in online search. Journal of e-Learning and Knowledge Society, 13(3).

- Rasinski, V. (2000): "Teaching Comprehension and Exploring Multiple Literacies: Strategies from the Reading Teacher. “ International Reading Association. ,89, (2), 151-161.

- Richard P. \& Linda E. (2016). Critical Thinking Competency Standards. Foreign

- Language Teaching and Research Press.

- Yuretich, F. R. (2004). Encouraging critical thinking: Measuring skills in large introductory science classes. Journal of College Science Teaching, 33(3), 40-46.

- Yurika, I. (2008): Developing Reading Fluency: A Study of Extensive Reading in EFL. Reading in a Foreign Language, 20, (1), 70-91.

\section{$* * *$}

